\title{
Comparing Alternative Methods of Measuring Geographic Access to Health Services: An Assessment of People's Access to Specialist Hospital in Kebbi State
}

\author{
Sa'ad Ibrahim \\ Department Of Geography, Adamu Augie College of Education \\ Argungu, Kebbi State, Nigeria
}

\section{Doi:10.5901/ajis.2013.v2n12p109}

\begin{abstract}
This paper presents comprehensive and analytical methodologies of Geographical Information Systems (GIS) in identifying geographic access to health service provision. It compares some alternative measures of geographic access to health care facility using spatial analysis. ArcGIS based network analysis (Origin and Destination Cost Matrix) was used to denote Output areas as the origin (demand) and hospital as the destination (supply). Raster based straight line distances (Euclidean) for same area was measured to identify this access. The accessibility of people within $60 \mathrm{~km}, 100 \mathrm{~km}, 200 \mathrm{~km}, 250 \mathrm{~km}$ and distances $\geq 300 \mathrm{~km}$ were assessed for both methods. The results for OD matrix stood at $29.77 \%(60 \mathrm{~km}), 42.48 \%(100 \mathrm{~km}), 53.78 \%(200 \mathrm{~km}), 72.99 \%$ $(250 \mathrm{~km})$ and $30.38 \%(\geq 300 \mathrm{~km})$ whereas, for the straight line distance, 39.99\% $(60 \mathrm{~km})$, $57.35 \%(100 \mathrm{~km}), 75.52 \%(200 \mathrm{~km}), 83.67 \%(250 \mathrm{~km})$ and $0.0 \%(\geq 300 \mathrm{~km})$ were recorded. The distance measurements were statistically not very strong $(p-0.07)$ between the methods. Moreover, travel time was also modelled at speed limit $50 \mathrm{~km}$ per hour using OD Matrix. The result indicates that only 33.35\% are within drive time of 80 minutes (1 hr. $20 \mathrm{~min}$.) and over $30 \%$ are within drive time $\geq 2$ hrs. $45 \mathrm{~min}$. Thus, the study encourages the use of OD Matrix in facility location analysis being more promising than the Euclidean model. The paper also strongly recommend to policy makers in the health service to embrace GIS to incorporate the technology of how service areas of health servers can be used as a basis for better use of population health service ratios to ensure equitable distribution of resources and effective health care delivery.
\end{abstract}

Keywords: Network Analysis: Straight Line Distances: Health Facility: Access

\section{Introduction}

In recent times, there is growing concern among decision makers, scientific researchers and politicians on the alternative measures to better the health care delivery system. In health service provision, the problems of the health care quality and accessibility are fundamental issues. Problems with accessibility to care would include evaluation of the adequacy of the numbers of health care facilities and the proper distribution of these facilities to ensure easy and immediate access to a health facility for every patient who needs one, the affordability, and therefore the accessibility of quality health care to all patients, etc. (Nwangwu, 2013). Today, lack of access to general health care by many communities in Nigeria is very pathetic, pervasive, and vulnerable. In many rural areas, health cases that require the attention of qualified medical practitioners are often handled by people who are very inexperienced. In this part of the country, many people cannot afford to see a specialist either because of poverty or lack of easy proximity to some of the secondary and tertiary institutions. This is due poor health care delivery system which makes availability, accessibility and affordability difficult to most people.

In addition, inequality and disparity in geographic accessibility might result due manner in 
which people and facilities are spatially arranged. And because health care delivery system has been subjected to considerable economic pressure, facilities cannot be located in all places. They are at finite fixed locations yet they serve populations that are continuously and unevenly distributed throughout a region. Due to this arrangement of population and facilities in space, inequality is rather very inevitable. However, in some scenarios, people have to travel distances longer than usual to gain access to health services as a result of the location of facilities coupled with poor road network system(( Delamater, et al. 2012: Allen 2013). In the past, the situation was much more compounded because the potential role of geographical information system in improving public health was not fully realised. This results due to lack of interaction between the GIS and health research community and recognition of the need for basic research in health and GIS (Campagna, 2006).

Currently, the increasing availability of Geographical Information Systems (GIS) in health organisations, together with the proliferation of spatially disaggregate data, has led to a number of studies that have been concerned with developing measures of access to health care services.(Higgs, 2009). Moreover, with the advancement of geographic information systems (GIS) and sophisticated computer technology, decision and policy making in facility site selection can be enhanced into a larger dataset with more complicated data structures, more accurate spatial measurement, spatial analysis and spatial modelling. GIS capability to represent spatial objects as points, line, or polygons has increased the flexibility of entity representations in facility location modelling (Indriasari, et al. 2010).

Thus, geographically based health care research commonly utilizes methodologies and measurements attainable using a geographic information system (GIS) which include network model (vector representation) and raster model (raster representation). These methods are used to measure distances and travel time between the locations of health facilities and people. For instance, distance from patients to hospital or estimate of access to care. However, measurement precision varies with method in question. Although, nowadays, the raster based measurement (straight line distance) is often replaced by more plausible methods such as the network analysis, the choice of a method is dependent of research question and units of measure within a study area (Jones, Ashby, \& Naidoo 2010: Delamater, et al. 2012).

In this piece, the purpose is exploring different methods used in accessibility studies. Specifically to calculate distances and travel time (at different impedances) using network model and distances using raster based method. It also sought to compare the resulting distances measured by the methods- Euclidean (straight line) and network analysis using origin and destination matrix (OD Matrix) to ascertain if significant differences exist between methods. The research is expected to be applied within future health researches despite its outcome.

\subsection{Access and geographic accessibility}

A veritable literature describing GIS based studies of accessibility are available in transport, heath, green space, high way studies, communication, disaster management, and general administration. Most of these researches are geared towards quantifying distances or travel times to evaluate access against certain criteria (Liu \& Zhu 2003: Ohta et al., 2007: Comber et al. 2008: Comber et al. 2009: Doriwala \& Shah 2010: Keshkamat 2007: Langford \& Higgs 2010: Sasaki et al., 2010: Stephen et al. 2010). Accessibility is defined by Paecz (2004)" as the potential for interaction between locations in space" Penchansky and Thomas (1981) identified five varied dimensions of access which were classified by Khan (1992) into spatial components (accessibility and availability) and aspatial components (affordability, accommodation, and acceptability). Thus, access to health care can be grouped into potential and realized delivery of services based on whether actual utilization data of the services is incorporated (realized) or based solely on the characteristics of the services offered-potential (Delamater, et al. 2012).. In whatever area, it is viewed; the motive behind accessibility studies is geared towards good assessment and evaluation thereby accelerating 
opportunities for fruitful decision-making and planning, helping policy makers to arrive at a rationalised decision to ensure equitable distribution of resources and effective services delivery.

\subsection{Data model}

It is defined "as the formalised equivalent of conceptual model used by people to perceived geographical phenomena" (Borough \& McDonnell 1998). The nerve centre of any GIS is the data model, which is a set of constructs for representing objects and processes in the digital environment of the computer. The GIS users interact with the operational GIS so as to carry out a number of tasks such as making maps, querying databases, facility site location and proximity analysis among others. Since the analysis to be perform in order to understanding the real world varies, the decision and choice of a given data model is influence by the nature of the real world phenomena being investigated. Because these phenomena have different characteristics, there is no single type of all-encompassing GIS data model that is best for all circumstances (Longley, et al. 2010).

\subsubsection{Network (Vector) Model}

In the network data model each objects in the real world first classified in the 2-D case point, lines, polygon or area. Points (e.g., wells, retail stores, hospital) are recorded as single coordinates pairs, lines (e.g., roads, streams) as a series of ordered coordinates pairs (also called polylines) and polygons (e.g., census tracts, soil areas) as one or more line segments that close to form polygon area. Much precision is associated with this model because vector data structure allows us to code the spatial characteristics and relationships between objects (points, lines, polygons) explicitly (i.e. topology). Therefore, network analysis which connotes a system of lines topologically structured is effective to understanding the spatial distribution and relationships of people to health facility. For instance, the network data model tries to reflect the actual vehicular travel time or distance considering that road segments (edges) are connected at road intersections (nodes), upholding real-world connectivity among locations ((Longley, et al. 2010: Delamater, et al. 2012).

\subsubsection{Raster Model}

Raster model represents geographic phenomena by array of rectangular cells or grids usually squared. The variation within the data is expressed by assigning properties or attributes to these cells (Longley, et al. 2010). Raster model is regarded as one of the attractive model for creating service areas, especially in regions without an all-encompassing transportation network (Delamater, et al. 2012).

\section{Method and Procedures}

\subsection{The study area}

Kebbi state is one of the seven states of the north-western geopolitical zone. It was carved out of the Sokoto state in August 27, 1991. Its capital is Birnin-Kebbi. The state composed of up to 35 districts divided into four emirates (Gwandu, Argungu, Zuru, and Yauri). Kebbi derived its name from the $14^{\text {th }}$ century "KEBBI KINGDOM" which was a province of the former Songhai Empire. The state occupies 37,727.97 square kilometres. It bordered Sokoto state in the North-Eastern part, Zamfara state on the Eastern part and Niger state on the south part and Republic of Niger on the Western part. The population of the people (predominantly rural) was 3,256,541 according to 2006 official census. Climate of the area is tropical continental type, thus, agriculture is the mainstay of the people. The state is blessed with large flowing rivers such as the Niger. www.kebbistate.gov.ng 


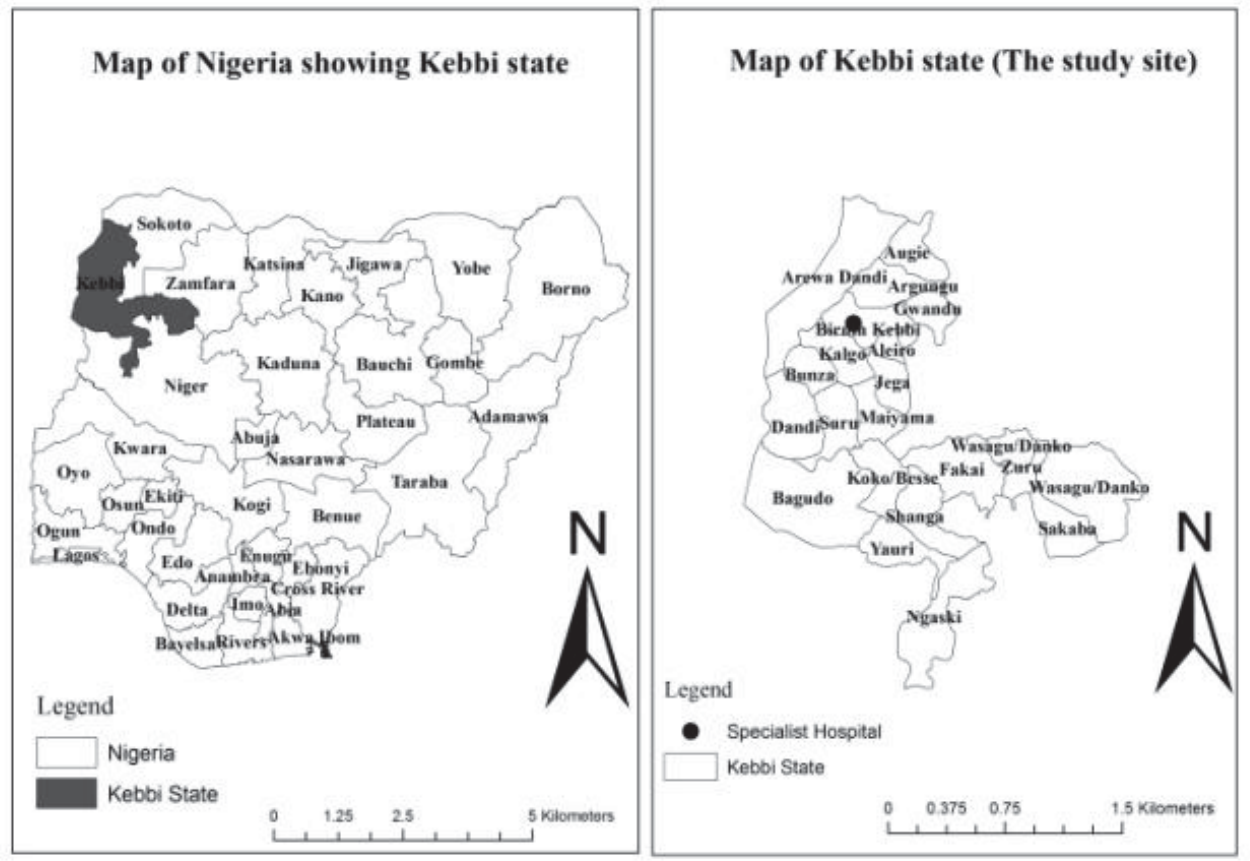

\subsection{Data description}

In order to establish base taking into cognisance the aims of this research, it is imperative to prepare datasets that are geographically referenced. GIS database was built in the computer environment which contains the following information.

- SPOT image: of 2009 is acquired from the United State Geological Survey (U.S.G.S) at the Earth Resources Observation and Science Centre (EROS) available at (http://www.glovis.usgs.gov).

- Specialist hospital: is point data digitised from SPOT image of 2009. The hospital is located in Birnin Kebbi, the headquarters of Kebbi state. This represents the facility from which distances and travel time were calculated in relation to the location of the people.

- Population Data: The latest census from which all population information was derived is 7 years old (since 2006). It is acquired from the official website of the National Population Commission of Nigeria (www.npc.gov.ng). The total number people in the state are $3,256,541$ people. The study therefore made projections to 2013 for the state. The annual growth rate of population for the state was $3.17 \%$, which is almost the same with the national average of $3.183 \%$.

- Road Network dataset: was digitised from SPOT image. First consideration was the selection of the major roads (high ways) then, other connecting roads that linked areas.

\subsection{Methods}

In this work, network based and raster methods were used and distances obtained from the two methods were compared using statistics. The shape files were first projected to Universal Transvers Mercator (UTM) to acquire the distances in meters. 


\subsubsection{Network Based Method}

In this work, origin and destinations matrix (OD Cost Matrix) was used to denote Output Areas as the Origin (Demand) and hospital as the Destination (Supply) using ArcGIS based network analysis. This calculates distances and travel time at different impedance. The output areas were first converted from feature to point to get the centroids. However, some output areas were not located due to poor road network connectivity, so their position was adjusted around the closest road near the centroid area. Road network dataset was built in the Arc catalogue (Arc Map environment). The output areas that are less than or equal $60 \mathrm{~km}, 100 \mathrm{~km}, 200 \mathrm{~km}, 250 \mathrm{~km}$, and greater than $300 \mathrm{~km}$ were obtained. For the travel time, the impedance was change from length to minutes. To calculate the travel time, different speed limits (kilometre per hour) were used. The output areas within 60 ( $1 \mathrm{hr}$ ) ), 120 (2 hrs.), 165 (2 hrs. 45 min.) and greater than or equal to 165 (2 hrs. 45 min.) minutes were obtained for speed limits 50 and 60 kilometres per hour respectively. The speed limit of 50 kilometres per hour does match the Federal Road Safety Corps (FRSC) regulations for higher ways. However, considering, the regulations as to the roads in rural areas couple with poor road network, the 50 kilometres per hour was also adopted to reflect the true situation of the travels within the study area.

\subsubsection{Raster Based Method}

In this part, the vector data used in the network analysis was converted to raster. Analysis path was set in the spatial analyst options of the Arc map and distances were calculated. The hospital data served as the reference point from which the calculations of output areas distances (population data) were made. The shape file which was converted from feature to points (representing the output areas) was overlay on the layer of the straight line distances. These enable us to compute distances of the output areas that are less than or equal $50 \mathrm{~km}, 100 \mathrm{~km}, 200$ $\mathrm{km}, 250 \mathrm{~km}$ and equal to or greater than $300 \mathrm{~km}$.

\section{Results}

The results of this analysis demonstrated the nature of the people's access (in terms of distances for both methods and specifically travel time using OD matrix) to this special health facility. The realities of this observable spatial pattern have been logically presented. Table 1 displays the results of the OD Cost Matrix computed for the distances between each origin and destination in line with proximity limit conditioned by these working criteria.

Table 1: Network analysis distances (OD cost matrix)

\begin{tabular}{|c|c|c|}
\hline Travel distance & Number of people & Percentages (\%) \\
\hline$\leq 60 \mathrm{~km}$ & $1,184,886$ & 29.77 \\
\hline$\leq 100 \mathrm{~km}$ & $1,548,164$ & 42.48 \\
\hline$\leq 200 \mathrm{~km}$ & $2,140,069$ & 53.78 \\
\hline$\leq 250 \mathrm{~km}$ & $2,762,260$ & 72.99 \\
\hline$\geq 300 \mathrm{~km}$ & $1,216,907$ & 30.38 \\
\hline
\end{tabular}

Of the total number of people within the state, only some $29.77 \%$ have access to this facility within $60 \mathrm{~km}$. over $50 \%$ of the people have access within $200 \mathrm{~km}$. And $30 \%$ recorded distances of $300 \mathrm{~km}$ and above. Different scenario can be observed in Table 2. As against the distances of the network OD Matrix, straight line distances recorded 39.99\% within $60 \mathrm{~km}, 75 \%$ within $200 \mathrm{~km}$ and $0 \%$ at $300 \mathrm{~km}$ and above. 
Table 2: Straight line (Euclidean) distances

\begin{tabular}{ccc}
\hline Travel distance & Number of people & Percentages $(\%)$ \\
\hline $\mathbf{5} \mathbf{6 0} \mathbf{~ k m}$ & $1,567,676.92$ & 39.99 \\
$\leq \mathbf{1 0 0} \mathbf{~ k m}$ & $2,282,258.71$ & 57.35 \\
$\leq \mathbf{2 0 0} \mathbf{~ k m}$ & $3,005,406.01$ & 75.52 \\
$\leq \mathbf{2 5 0} \mathbf{~ k m}$ & $3,329,540.65$ & 83.67 \\
$\geq \mathbf{3 0 0} \mathbf{~ k m}$ & 0.00 & 0.00 \\
\hline
\end{tabular}

Table 3 shows the calculated travel time that people have to travel to gain access to the health facility. The speed limit values (50 kmph) of the input road data, does not matches the national standard for the higher ways. The reason being that despite some roads are not high ways, there is also poor road network connectivity which is linked to the higher ways. Thus, only $33 \%$ are within 80 minutes' drive time. Over 55\% are within $2 \mathrm{hrs} 45$ minutes drive time and $30 \%$ of the people recorded travel time greater than 2 hrs. 45 minutes.

Table 3: Network analysis travel time (Speed limit 50kmph)

\begin{tabular}{|c|c|c|}
\hline Travel Time & Number of People & Percentage (\%) \\
\hline$\leq 80 \mathrm{~min} / 1 \mathrm{hr} .2$ & $1,327,076.264$ & 33.35 \\
\hline$\leq 120 \mathrm{~min} / 2 \mathrm{hr}$ & $1,922,183.109$ & 48.30 \\
\hline$\leq 165 \mathrm{~min} / 2 \mathrm{hrs} .45 \mathrm{~min}$. & $2,213,012.416$ & 55.61 \\
\hline$\geq 165 \mathrm{~min} / 2 \mathrm{hrs} .45 \mathrm{~min}$ & $1,2273,57.005$ & 30.84 \\
\hline
\end{tabular}

\subsection{Correlation test}

The distance measurements to the health facility were statistically not very strong $(p-0.7)$ between the OD Matrix and Euclidean distances for all people in the study area.

\section{Discussion and Conclusion}

This study used the network analysis (OD Cost Matrix) and straight line distances (Euclidean) in order to analyse the geographical accessibility of people to specialist hospital. GIS was used to establish a set of criteria to be used for the decision-making process. Although, there are few studies that have been conducted in Nigeria regarding health care facilities location, quite a number of them succeeded only in addressing hospital distribution in terms of the direct distance between two points on a map using either network analysis or straight line distances. In order compare different methods to obtain more precise information, the present study targeted specialist hospital in Kebbi State, which is expected to serve all people especially for referral cases that require the attention of an expert medical practitioner.

The Euclidean method revealed that more people are served by the facility than the network analysis (OD Cost Matrix). Using the network analysis, over $30 \%$ were found to be at a distance of $300 \mathrm{~km}$ or more and $30 \%$ having travel time over $2 \mathrm{hrs}$. $45 \mathrm{~min}$. In contrast to this scenario, none were recorded by the Euclidean method in that order. This is the most extreme differences between the methods. The distances as calculated by statistics between methods are not highly correlated ( $p$ - 0.07). This is not completely unexpected since network model is more objective and scientific (Kofie \& Jensen 2010) than the Euclidean. Even where the calculations of Euclidean distances are seem accurate, its limitation is that it does not consider the nature of the physical features such as lakes, rivers, and mountains and wilderness. In Boscoe, et al. 2012, the results of network analysis was highly correlated with straight line (in the United States) having $r^{2}$ values of 0.9. In contrast to Boscoe, et al. 2012, this study suggests that straight line distance should not be 
used as a proxy of drive distance in Kebbi state. The high correlation recorded in Boscoe, et al. 2012, may be attributed to the high clustering of road networks in the US.

The results of drive and Euclidean distances analysis indicated a clear marked disparity in terms of geographic access to health facility among the people in the study area. The facility being a specialist centre has a profound impact to the lives of the people within the state. The basic fact is that since everyone makes regular visit to the hospital or visit the hospital through referral services being the specialist hospital, the research considered a large proportion of the people to be underserved with the drive distance of just $42 \%$ within $100 \mathrm{~km}$, Euclidean $53 \%$ within $100 \mathrm{~km}$, and drive time of only $48 \%$ within 2 hours. In Ghana, this type of hospital is regarded as the Blevel facility, the referral level for the communities' health workers and is intended to cover a radius of $8 \mathrm{~km}$ (Kofie \& Jensen 2010). In Nigeria, it appears that geographic access is not being considered in locating such facilities. Thus, optimisation model of GIS can be adopted to determine how large could the area be served using algorithms in order to optimize this single facility to maximised benefits (Indriasari, et al. 2010). Also to incorporate GIS technology of how service areas of health servers can be used as a basis for better use of population health service ratios to ensure equitable distribution of resources and effective health care delivery (Bamford \& Hugo 2001)

In this study, and in all cases, there are implications with the results of the research due limitations of the data used. The population data for which this study relied upon was purely not geo-coded based on census enumeration units. The least that is obtainable at the population commission's level, is the local government population data embodied as a single entity representing 100 thousands of people (including villages and other far remote areas). It is too large for the exact distances to be calculated in all areas. Some rural areas within the local government might be as far as $100 \mathrm{~km}$ from the main town. In this case, however, with GIS, dasymetric (using ancillary population data,) and pycnophylactic methods of population estimation can be applied. This requires learning new techniques.

A sharp contrast to this situation can be seen in the UK, the Ordinance Survey (OS) is the Great Britain's national mapping agency, providing the most accurate and up-to-date geographic data, relied on by government, business and individual. While the Royal Mail, is the UK's postal agency with over 350 years of operational history. Thus, royal mail suppliers the address in the database in the form of PAF (Postal Address File), OS simply attaches a GPS point to the address. Today, Britain has Ordinance Survey's Master Map Address Layer 2 database. This is the Britain's most complete, comprehensive and reliable national dataset of addresses and building and their precise locations. This is classical example of how institutions in Nigeria can work together towards a common goal. The Nigerian mapping agency supposed to be the equivalence UK's OS while NIPOST is the Nigerian equivalence of UK's Royal Mail. (Ajala, 2013).These data are very enormous and can be used not only for research in geographic access of facility location but also for banks, insurance company, utilities, transport, emergency services and crime to mention just a few. This is really a milestone and will no doubt increase the quality and reliable of similar researches.

In conclusion, despite the shortcomings of the data, the use of network analysis is highly recommended and that the findings of this research are still useful. Thus, the analytical methods introduced in this study can be adopted in health service provision for good decision and policy making to ensure adequate access to facilities and effective health care delivery system.

\section{References}

Ajala, I. (2013, May 20). National address gazeteer of Nigeria- An aid to national development and a100 million missed business opportunities for Nigerian postal agency $\&$ office of the surveyor general of Nigeria . Lagos, Nigeria

Allen, C. (2013, June 23). Using raster GIS to evaluate hospital catchment areas based on travel Time in North Central Massachusetts and South Central New Hampshire. 
Bamford, E., \& Hugo, G. (2001). Identifying gaps in health service. 6th National Rural Health Conference. Canberra.

Borrough, P., \& McDonnell, R. (1998). Principles of Geographic Information Systems, . Oxford: OUP.

Boscoe , F. P., Henry , K. A., \& Zdeb, M. S. (2012). A Nationwide comparison of driving distance versus straight-line distance. The proffessional Geographer, 188-196.

Campagna, M. (2006). GIS for sustainable development. United State of America: Taylor and Francis Group.

Comber, A., Brunsdon, C., \& Green, E. (2008). Using a GIS-based network analysis to determine urban greenspace accessibility for different ethnic and religious groups. Landscape and Planning, 103-114.

Comber, A. J., Brunsdon, C., Hardy, J., \& Radburn, R. (2009). Using GIS based network analysis and Optimisation routines to evaluate service provision: a case study of the UK post offfices. Applied Spatial Analysis and Policy, 47-64.

Delamater, P. L., Messina, J. P., Shortridge, A. M., \& Grady, S. C. (2012). Measuring geographic access to health care: Raster and network-based methods. International Journal of Health Geographics, 11-15.

Doriwala, H., \& Shah, N. (2010). GIS- Based analysis of facility provision accessible to different socioeconomic groups in surat city. World Applied Sciences, 740-745.

Galleria Media Limited. (2013, 06 10). Nigeria Galleria. Retrieved from http://www.kebbistate.gov.ng.

Higgs, G. (2004). A literature review of the use of GIS-Based measures of access to health care services. Health Services and Outcomes Research Methodology, 119-139.

Indriasari , V., Mahmud, A. R., Ahmad, N., \& Shariff, A. M. (2010). Maximal service area problem for optimal siting of emergency facilities. International Journal of Geographical Science, 213-230.

Jones, S. G., Ashby, A. J., \& Naidoo, A. (2010). Spatial implications associated with using euclidean distance measurements and geographic centroid imputation in health. Health Serv Res, 316-327.

Keshkamat, S. (20007). Formulation and evaluation of transportation planning alternatives using spatial multi criteria assessment and network analysis: a case study of Via Baltic express way in Norteastern Poland. Poland.

Khan , A. A. (1992). An integrated approach to measuring potential spatial access to health care services. Socio-Economic Planning Sciences, 275-287.

Kofie, R. Y., \& J essen, L. M. (2001). Towards a framework for delineating sub-districts for primary health care administration in rural Ghana: A case study using GIS. Norwegian Journal of Geography,26-33.

Langford, M., \& Higgs, G. (2010). Accessibility and public service provision: evaluating the impacts of the Post Office Network Change Progamme in the UK. Royal Geographical Society, 585-601.

Liu , S., \& Zhu, X. (2003). Accessibility Analyst: An integrated GIS tool for accessibility analysis in urban transportation planning. Environment and Planning, 105-124.

Longley, P. A., Goodchild, M. F., Maiguire, D. J., \& Rhind, D. W. (2010). Geographical Information Systems and Science. U.S.A: J ohn Wileys and Sons.

National Population Commission. (2013, 07 12). 2006 Population and Housing Census. Retrieved from http://www.npc.gov.ng.

Nwangwu, P. (2013). Health delivery in Nigeria: contribution of Nigerians in diaspora. France.

Ohta , K. A., Kobashi , G. B., Takano, S., Kagaya , S. D., Yamada, H., Minakami, H., \& Yamamura, E. (2007). Analysis of the geographical accessibility of neurosurgical emergency hospitals in Sapporo city using GIS and AHP. International journal of geographical information science, 687-698.

Paecz, O. (2004). Network accessibility and the spatial distribution of economic activity of the Eastern Asia. Urban studies Journal Ltd, 2211-2230.

Penchansky, R., \& Thomas, J. W. (1981). The concept of access: definition and relationship to consumer satisfaction. Medical care, 127-140.

Sasaki, S., Comber, A. J., Suzuki, H., \& Brunsdon, C. (2010). Using genetic algorithms to optimise current and future health planning - the example of ambulance locations. International Journal of Health Geographics, 9-4.

United State Global Satellites . (2013, 02 26). Retrieved from global visualisation viewer: Http://www.glovis.usgs.gov. 